\title{
PERSONAGENS COM DEFICIÊNCIA NOS QUADRINHOS DE MAURICIO DE SOUSA: DIVERSÃO E RESPEITO Ầ DIFERENÇAS ${ }^{1}$
}

\author{
Michelle Silva de Mattos ${ }^{2}$
}

\begin{abstract}
RESUMO
Em todo o mundo existem pessoas com algum tipo de deficiência, e a criação de legislações em defesa da inclusão tem favorecido sua inserção na sociedade. Apesar dos avanços, existe ainda um longo caminho a ser percorrido, sobretudo no que tange ao tratamento igualitário em relação aos demais indivíduos, pois o imaginário social acerca das pessoas com deficiência como incapazes e desprotegidas contribui para que as diferenças sejam acentuadas ainda na infância. Ao perceber a necessidade de modificação dessa realidade, o cartunista Mauricio de Sousa inseriu personagens com deficiência em suas histórias com o propósito de mostrar que elas têm a mesma capacidade de aprender, brincar, e conviver com as outras crianças. Assim, com base na Teoria das Representações Sociais e seu caráter dinâmico, o presente trabalho tem por objetivo mostrar de que maneira os quadrinhos da Turma da Mônica podem contribuir para a desconstrução de crenças e preconceitos vigentes e atuar na reconstrução de valores favoráveis à independência e capacidade das pessoas com deficiência.
\end{abstract}

PALAVRAS-CHAVE: deficiência. representações sociais. educação especial. histórias em quadrinhos.

\begin{abstract}
All over the world there are people with some kind of disability, and the creation of legislation in defense of inclusion has favored their integration into society. Despite the advances, there is still a long way to go, especially with regard to equal treatment in relation to other individuals, for the social imaginary about people with disabilities as incapable and unprotected helps to increase the differences even during childhood. After realizing the need to change this reality, cartoonist Mauricio de Sousa inserted disabled characters in his stories with the purpose of showing that they have the same ability to learn, play, and coexist with the other kids. Thus, based on the Theory of Social Representations and its dynamic character, this work aims to show how Monica's Gang comics can contribute to the deconstruction of beliefs and prejudices in force and act in favor of the reconstruction of values favorable to the independence and capacity of the people with disabilities.
\end{abstract}

KEY WORDS: disability. social representations. special education. comic books.

\section{Introdução}

Em diversos países, o debate em defesa da inclusão como um dos direitos humanos levou à criação de legislações específicas, como a Lei de Inclusão da Pessoa com Deficiência, no Brasil. Essa lei destina-se a "assegurar e promover, em condições de igualdade, o exercício dos direitos e das liberdades fundamentais por pessoa com deficiência, visando à sua inclusão social e cidadania" (BRASIL, 2015).

As inovações trazidas pela lei promoveram avanços na esfera da educação, trabalho, assistência social, saúde entre outros. Todavia, ainda existem muitas barreiras que dificultam a

\footnotetext{
${ }^{1}$ A autora agradece a Maria de Fátima Souza Santos e às demais autoras da pesquisa por autorizarem o uso das ilustrações de seu artigo no presente trabalho.

${ }^{2}$ Mestre em Linguística Aplicada pela Universidade Federal do Rio de Janeiro (UFRJ). Professora do Instituto Superior Anísio Teixeira (ISAT) - michellesottam@gmail.com
} 
autonomia das pessoas com deficiência, como a falta de acessibilidade e o preconceito social. Este parece ser fruto da prática cultural exclusivista construída historicamente ao longo dos $\operatorname{anos}^{3}$, que privava esses indivíduos do convívio social e os considerava incapazes de exercer alguma atividade profissional para garantir seu próprio sustento. Para fins de delimitação do tema, a próxima seção destina-se a apresentar as variações na linguagem utilizada para se referir às pessoas com deficiência ao longo da história.

\section{A pessoa com deficiência}

Ao se observar alguns dos termos que já foram utilizados para se referir à pessoa com deficiência, é possível constatar que o uso das palavras e expressões variou ao longo dos tempos, de acordo com a percepção da sociedade em relação a esses indivíduos. Conforme destaca Sassaki (2005, n.p.), “jamais houve ou haverá uma única expressão correta, válida definitivamente em todos os tempos e espaços.” Em sua publicação, o autor traça um panorama histórico para mostrar a utilização das palavras conforme sua compatibilidade com os valores vigentes em determinado período.

Exemplificando, após a $1^{\mathrm{a}}$ e $2^{\mathrm{a}}$ guerras mundiais, os termos os incapacitados ou os incapazes eram usados pela mídia em referência àqueles que não eram capazes de realizar determinada atividade em função de sua deficiência.

No final da década de 1950, a fundação da Associação de Assistência à Criança Defeituosa (AACD), hoje denominada Associação de Assistência à Criança Deficiente, levou a sociedade a utilizar três termos que focalizam as deficiências em si: defeituosos, ("indivíduos com deformidade", sobretudo física), deficientes ("indivíduos com deficiência" em geral), e excepcionais (“indivíduos com deficiência intelectual”).

Mais tarde, a Organização das Nações Unidas (ONU) determinou 1981 como ano internacional das pessoas deficientes. Contudo, a palavra "deficiente" não foi bem recebida pela população em geral, e isso pode ter sido um dos indicadores de uma mudança de percepção em relação a esses indivíduos. Líderes de organizações de pessoas com deficiência

\footnotetext{
${ }^{3}$ Em seu estudo, Lopes (2013) traça um panorama histórico acerca do preconceito com o deficiente, desde a Grécia antiga (por volta de 480 a.C.) com o propósito de mostrar como a expansão do Império Romano na Europa pode ajudar na compreensão da modificação na forma como esses indivíduos passaram a ser vistos pela sociedade, persistindo até os dias de hoje. De acordo com o autor, o entendimento deste processo pode ajudar a compreender de onde se originam certos pré-julgamentos e atitudes discriminatórias contra a pessoa com deficiência.
} 
contestaram a expressão "pessoa deficiente" alegando estigmatização, como se o indivíduo inteiro fosse deficiente. Em substituição, o termo "pessoas portadoras de deficiência" indicando que isto seria um aspecto da pessoa - ganhou espaço no final da década, tendo sido adotado na Constituição Federal em 1988 e em todas as leis e políticas públicas. Todavia, a aceitação do termo não foi unânime, e sim alvo de questionamento, conforme explicado por Sassaki (2013, n.p.):

\begin{abstract}
A condição de ter uma deficiência faz parte da pessoa e esta pessoa não porta sua deficiência. Ela tem uma deficiência. Tanto o verbo "portar" como o substantivo ou o adjetivo "portadora" não se aplicam a uma condição inata ou adquirida que faz parte da pessoa. Por exemplo, não dizemos e nem escrevemos que uma certa pessoa é portadora de olhos verdes ou pele morena. Uma pessoa só porta algo que ela possa não portar, deliberada ou casualmente. Por exemplo, uma pessoa pode portar um guarda-chuva se houver necessidade e deixá-lo em algum lugar por esquecimento ou por assim decidir. Não se pode fazer isto com uma deficiência, é claro.
\end{abstract}

Na tentativa de amenizar a contundência da palavra deficiência, ao longo da década de 1990, popularizaram-se alguns termos de caráter mais suavizador, como necessidade especial e pessoas especiais. Posteriormente, Sassaki (2005) chamaria a atenção para a necessidade de se combater tais neologismos, idealizados na tentativa de minimizar as diferenças.

O referido autor (2014) aponta que "o fim da década de 1990 e a primeira década do século XXI foram marcados por eventos mundiais liderados por organizações de pessoas com deficiência". Entre os assuntos a serem discutidos estava o debate acerca do nome pelo qual essas pessoas desejam ser chamadas. O consenso foi de que seriam referidas como "pessoas com deficiência" em todos os idiomas, e essa expressão faz parte do texto da Convenção Internacional para Proteção e Promoção dos Direitos e da Dignidade das Pessoas com Deficiência, aprovado pela ONU em 2006. Cabe resumir a seguir os princípios básicos que nortearam a preferência dos movimentos pelo termo em questão (Sassaki, 2005):

1. Não esconder ou camuflar a deficiência;

2. Não aceitar o consolo da falsa ideia de que todo mundo tem deficiência;

3. Mostrar com dignidade a realidade da deficiência;

4. Valorizar as diferenças e necessidades decorrentes da deficiência;

5. Combater neologismos que tentam diluir as diferenças, tais como pessoas com capacidades especiais, pessoas com eficiências diferentes, pessoas com habilidades diferenciadas, pessoas deficientes, pessoas especiais. 
6. Defender a igualdade entre as pessoas com deficiência e as demais pessoas em termos de direitos e dignidade no que tange à equiparação de oportunidades e consideração às suas diferenças individuais e necessidades especiais.

7. Identificar nas diferenças todos os direitos que lhes são pertinentes e a partir daí encontrar medidas específicas para o Estado e a sociedade diminuírem ou eliminarem as "restrições de participação" (dificuldades ou incapacidades causadas pelos ambientes humano e físico).

Atualmente, o termo "pessoa com deficiência" consta no texto da Lei Brasileira de Inclusão da Pessoa com Deficiência (BRASIL 2015), que caracteriza como pessoas com deficiência aquelas que têm impedimentos de longo prazo de natureza física, mental, intelectual ou sensorial, cuja participação efetiva na sociedade em igualdade de condições com as demais pode ser comprometida quando em interação com diversas barreiras.

Enfim, a motivação para esta seção está representada na asseveração de Silva (2009, n.p), ao expressar o papel da linguagem na expressão do olhar da sociedade sobre as pessoas com deficiência: "a construção de uma verdadeira sociedade inclusiva passa também pelo cuidado com a linguagem. $\mathrm{Na}$ linguagem se expressa, voluntária ou involuntariamente, o respeito ou a discriminação em relação às pessoas com deficiência".

\section{Personagens com deficiência nos quadrinhos de Mauricio de Sousa}

O mais famoso e premiado autor brasileiro de história em quadrinhos, Mauricio de Souza, desejava viver profissionalmente do desenho desde muito jovem. Em 1954, aos 19 anos de idade, procurou emprego de desenhista em São Paulo, mas só conseguiu uma vaga de repórter policial na Folha da Manhã. Passou cinco anos escrevendo esse gênero de reportagem, que ilustrava com desenhos bem aceitos pelos leitores.

Em 1959, Mauricio de Souza convenceu o editor a publicar uma tirinha semanal com seu primeiro personagem, o cãozinho Bidu. Em seguida foi criado o seu dono, o Franjinha; e nos anos seguintes foram surgindo novos personagens e mais tiras. Finalmente, em 1970, o cartunista lançou a revista da Mônica, e as histórias e os personagens se transformaram em um grande sucesso. Atualmente, entre quadrinhos e tiras de jornais, suas criações chegam a cerca de 30 países, e no mercado brasileiro, suas revistas são responsáveis por $86 \%$ das vendas (FRAZÃO, 2018). Há, ainda, filmes e curtas-metragens, parque de diversões, além de brinquedos, material escolar e outros produtos licenciados da Turma da Mônica. Além do aspecto comercial, Fortunato (2010) acrescenta que a popularidade da Turma também facilita 
a divulgação de projetos e campanhas sócio-educativas, como segurança no trânsito, prevenção a doenças e exploração sexual de crianças.

As histórias em quadrinhos da Turma da Mônica se passam no fictício Bairro do Limoeiro e se baseiam, acima de tudo, na amizade entre os personagens. Vasconcelos (2014, n.p) acrescenta que elas "sempre abordaram temas atuais, com mensagens educacionais e de respeito ao meio ambiente e à natureza, além de campanhas de saúde." Sendo um indivíduo sempre adepto às mais diversas causas sociais, ainda na década de 1960, Mauricio de Souza idealizou o personagem Humberto, um deficiente auditivo que se comunica com os colegas fazendo hum hum. A intenção do criador foi homenagear as milhares de crianças surdas que existem e que, mesmo sem poder falar, são ativas, saudáveis, e brincam como qualquer criança. Em uma história publicada na revista de número 239 em 2006, o personagem começou a se comunicar em LIBRAS (Linguagem Brasileira de Sinais), de modo que as crianças leitoras, ao contemplarem essa história, tiveram a oportunidade de conhecer o básico da forma de comunicação dos surdos, conforme na ilustração a seguir:

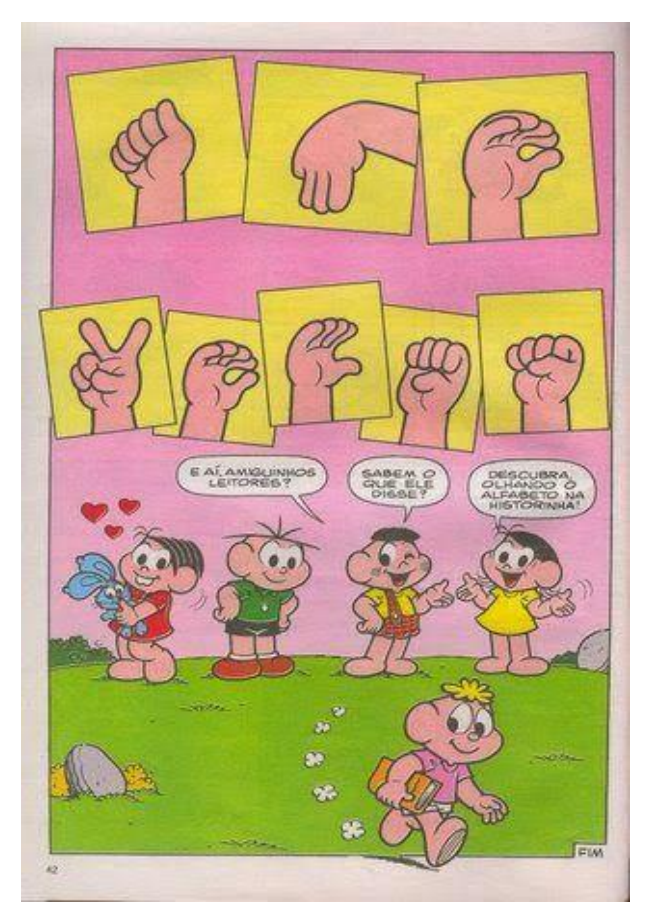

Figura 1 - Humberto diz “Amo vocês” em LIBRAS (revista 239)

Fonte: https://br.pinterest.com/pin/342203271670902314/

O personagem Hamyr apareceu pela única vez em 1989. O menino tinha uma deficiência física e usava um par de bengalas; mesmo assim, fugiu do controle da mãe para brincar com as outras crianças na rua, conforme lembrado por Ribas (2011). Em uma entrevista à página da internet Vida mais Livre (2012), Mauricio de Sousa não especificou o 
motivo da descontinuidade do personagem, mas reconheceu que havia a necessidade de manter esse tipo de interação, e o espaço foi preenchido anos mais tarde por um personagem cadeirante.

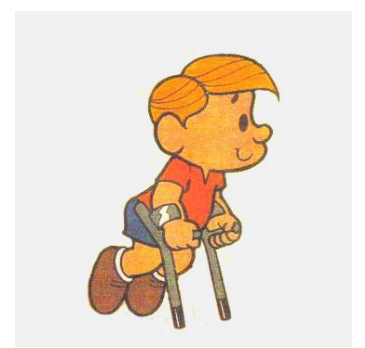

Figura 2 - Hamyr, o personagem esquecido.

Disponível em: https://www.criancasespeciais.com.br/wp-content/uploads/2019/04/hamyrcut.jpg

A criação do personagem André, em 2003, surgiu a partir de uma parceria entre o Instituto Mauricio de Souza e a Associação dos Amigos do Autista (AMA). O objetivo foi criar uma campanha que alertasse pais, familiares, e professores a respeito do que é o Transtorno do Espectro Autista ${ }^{4}$ e quais são suas características. A primeira aparição do menino foi em uma edição de conteúdo institucional chamada Um Amiguinho Diferente, e atualmente o personagem vem ganhando mais espaço, tendo suas histórias publicadas na Revista Autismo e aparecendo em animações lançadas pelo Instituto Mauricio de Sousa, com informações para ajudar na identificação precoce de alguns sinais e sintomas, além de sugestões para promover a inclusão e a convivência social dessas pessoas (REVISTA AUTISMO, 2019).

André tem quatro anos, é divertido, e curioso, desempenha algumas atividades melhor do que as crianças de sua idade, e quase não fala. Quando o faz, por vezes repete frases ou palavras que ouviu de outras pessoas ${ }^{5}$. Algumas de suas características geram estranhamento entre os colegas da Turma, como a repetição de gestos sequenciais (na figura abaixo, observase o ato de enfileirar o giz). Ao mesmo tempo, isso não o impede de estar na companhia de outras crianças:

\footnotetext{
${ }^{4}$ Embora o Transtorno do Espectro Autista não seja classificado como uma deficiência e sim um transtorno ou distúrbio do neurodesenvolvimento (CAMPOS e PICCINATO, 2019), optou-se por mencionar o personagem André neste trabalho como exemplo de mais um momento em que a preocupação de Mauricio de Sousa com que as crianças convivam com as diferenças foi manifestada.

${ }^{5}$ A ecolalia é uma característica relativamente presente na vida de uma criança autista, segundo Campos e Piccinato (2019)
} 


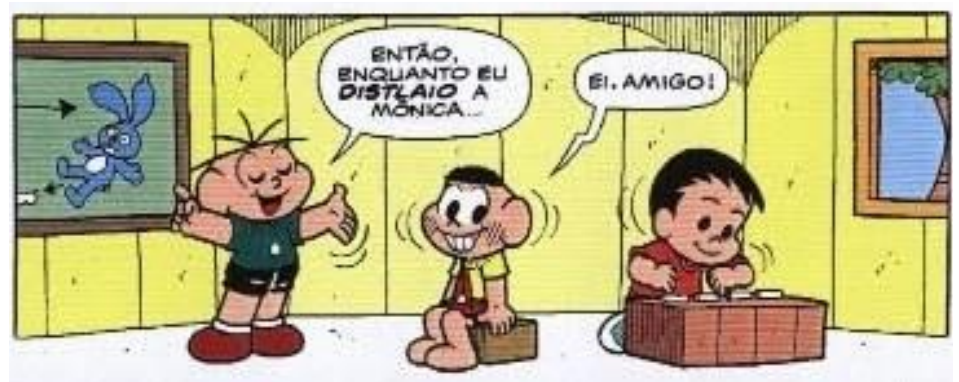

Figura 3 - Gesto sequencial do André

Fonte: https://www.psicologiasdobrasil.com.br/content/uploads/2019/02/andr\%C3\%A92.jpg

Em 2004, surgiram dois personagens com deficiência: Luca e Dorinha. Ele é um garoto cadeirante, amante dos esportes, principalmente o basquete. Para os amigos, o fato de ser cadeirante não o impede de participar das brincadeiras ou de ser alvo dos olhares apaixonados das meninas, principalmente da Mônica. Nas histórias do Luca são mostradas algumas situações em que ele tem dificuldades para se deslocar com a cadeira de rodas, como em calçadas esburacadas ou sem rampa - problemas comumente enfrentados pelos cadeirantes na vida real; porém, tudo é mostrado sempre de forma leve e bem-humorada. Para criar o personagem, Mauricio de Sousa foi conversar com atletas paraolímpicos e construiu a personalidade do menino a partir da observação do entusiasmo e alegria com que eles levam a vida (VASCONCELOS, 2014).

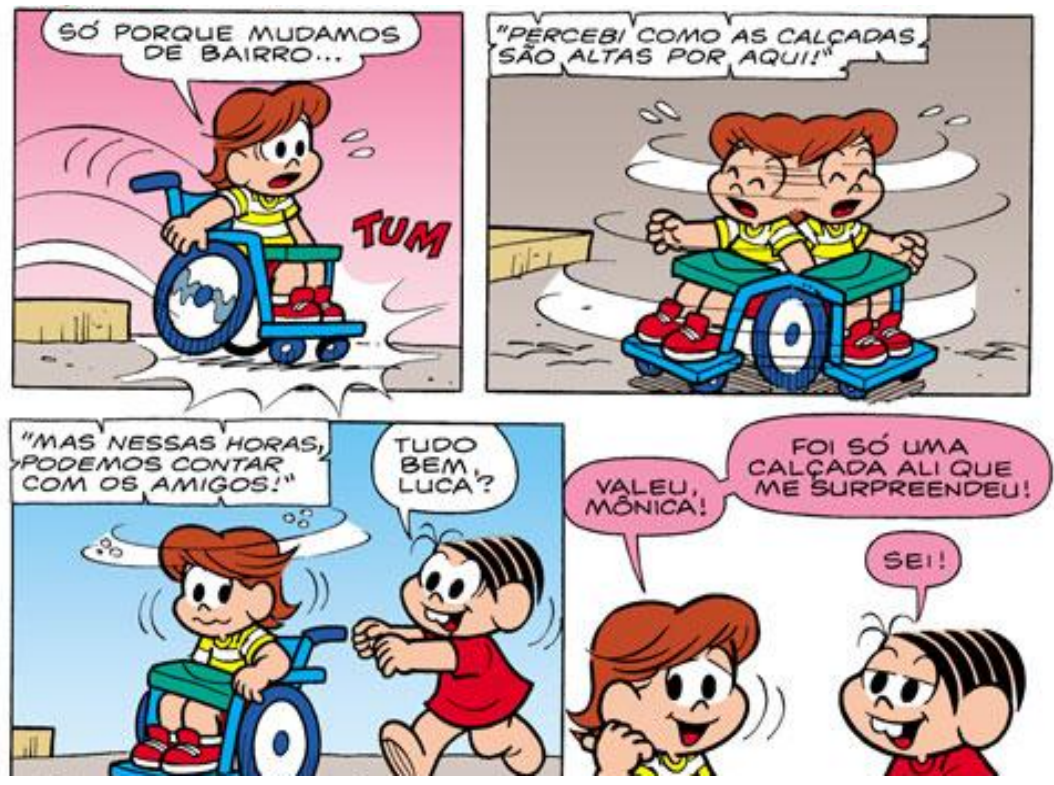

Figura 4 - Desafios do Luca (revista 222)

Fonte: http://turmadamonica.uol.com.br/acessibilidade/7.jpg 
A personagem Dorinha é cega, mas é capaz de reconhecer os amigos com precisão, pois tem a audição, tato, e olfato muito apurados. É uma menina extrovertida, inteligente, e participa de várias aventuras da Turma da Mônica. Seu cachorro, Radar, é um labrador que a ajuda a se guiar. Mauricio de Sousa conta que a personagem foi inspirada em Dorina Nowill, fundadora da respeitada instituição que leva seu nome e, há mais de sessenta anos, atua na inclusão de pessoas com deficiência visual (VASCONCELOS, 2014).

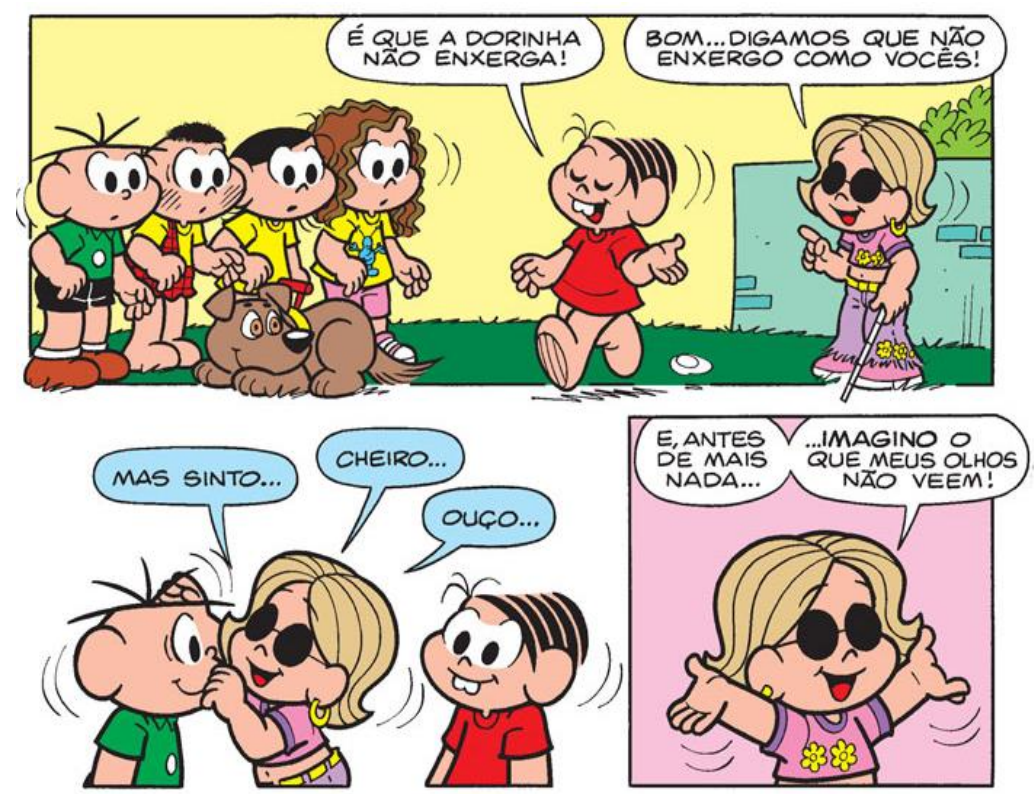

Figura 5 - Apresentação da Dorinha (revista 221)

Fonte: http://turmadamonica.uol.com.br/dorinhaanovaamiguinha/10.jpg

Criada em 2009, a personagem Tati tem síndrome de Down. A menina foi inspirada em Tathiana Heiderich, filha de Patrícia e Fernando Heiderich, coordenadores do Instituto MetaSocial, que trabalha há mais de 19 anos desenvolvendo ações junto à mídia para promover a inclusão social das pessoas que têm a mesma síndrome. Em parceria com a organização, o Instituto Mauricio de Sousa lançou a revista especial Viva as diferenças!, onde a personagem apareceu pela primeira vez, e a edição foi distribuída gratuitamente para associações e consultórios que tratam de pessoas com Síndrome de Down. Tati possui as características físicas associadas à síndrome, como ter olhos amendoados e ser um pouco menor que as crianças da sua idade. Sua personalidade é alegre, e ela sempre encontra saídas inteligentes e divertidas para qualquer situação. 


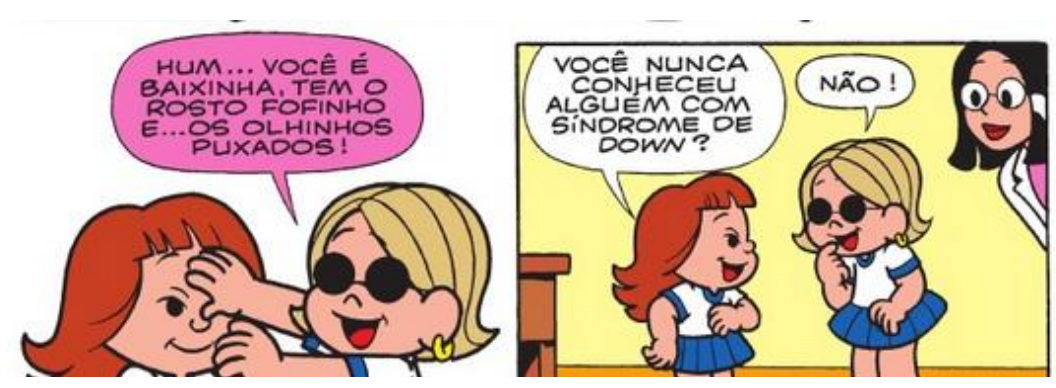

Figura 5 - Tati, a nova amiguinha (revista Viva as diferenças!)

Fonte: http://www.movimentodown.org.br/down-por-ai/quadrinhos/

Na já mencionada entrevista dada à página da internet Vida Mais Livre, o criador da personagem sintetiza o aumento de seu interesse por personagens com deficiência:

\begin{abstract}
A Turma da Mônica é um grupo de personagens que vivem e agem como crianças normais, como nossos filhos ou conhecidos. Todos nós temos amigos com algum tipo de deficiência e convivemos harmônica e dinamicamente. Aprendemos as regras da inclusão aí. Consequentemente, não poderíamos deixar de apresentar, no universo dos nossos personagens, amiguinhos da turma que também tivessem algum tipo de deficiência. Até acho que demorei muito para perceber esse vazio nas nossas histórias (SOUZA, 2012).
\end{abstract}

Posteriormente, na VIII Semana de Valorização da Pessoa com Deficiência, em 2014, outra declaração de Mauricio de Sousa é complementar: "Me dei conta de que faltavam personagens com deficiência na Turma, o que era um contrassenso, já que as nossas histórias em quadrinhos refletem a vida das crianças, que merecem ser tratadas sem preconceito nenhum" (EVIDENCIADOR, 2019, on-line).

Dall'Agnol (2008) aponta que nas histórias da Turma da Mônica, os personagens com deficiência não vivenciam situações conflituosas advindas de preconceitos ligados à sua condição. Ao contrário, todas as crianças “interagem com os deficientes de tal forma que a cegueira e a paralisia acabam sendo reduzidas a meras particularidades, representadas como características pouco relevantes.” (ibidem, p. 46) Enfim, Mauricio de Sousa demonstra estar cada vez mais comprometido com a ideia de que os quadrinhos não apenas contam uma história, mas são também instrumentos de compreensão de valores e ideologias da sociedade onde circulam. Ademais, podem também contribuir para uma possível mudança social ${ }^{6}$.

\footnotetext{
${ }^{6}$ O trabalho de Fontana e Araújo (2011), que tem como foco a personagem Dorinha, menciona personagens como O Patinho Feio, Dumbo e Nemo, a fim de exemplificar alguns dos momentos em que a literatura infantojuvenil demonstrou preocupação com a formação da criança para conhecer e aceitar o "diferente" em suas histórias.
} 


\section{Teoria das Representações Sociais}

O psicólogo social romeno naturalizado francês Serge Moscovici tinha como objeto de estudo a interação entre a psicanálise e as ciências sociais, particularmente o tema da relação entre grupos, atos e ideias. Conforme demonstrado por Oliveira (2004, p.181), o estudioso desejava compreender "como a produção de conhecimentos plurais constitui e reforça a identidade dos grupos, como influi em suas práticas e como estas reconstituem seu pensamento".

No início da década de 1960, na França, Moscovici desenvolveu a teoria das Representações Sociais, que:

[...] consistem em um conjunto de valores, noções e práticas que permitem ao indivíduo o controle do meio social e material e a sua orientação nesse meio, além de assegurar a comunicação social por propor um código compartilhado pelos membros de uma comunidade, possibilitando trocas sociais (MOSCOVICI, 1986 apud VASCONCELLOS et al., 2011, p.279).

Rodrigues e Melo (2012, p. 34) explicam que as representações sociais são construídas a partir da vida coletiva; assim, permitem a identificação de valores, ideologias, e crenças populares. Baseando-se em Guareshi e Jovchelovitch (2002, p. 20), os autores complementam que as representações podem ser formadas na interação entre os indivíduos, ou ainda, diante da exposição "às instituições, aos meios de comunicação, aos mitos, e à herança histórica e cultural de suas sociedades". Assim, conforme os conhecimentos são compartilhados e internalizados, o indivíduo concebe sua identidade individual, e ao mesmo tempo social. Cabe destacar que, conforme a evolução de uma determinada sociedade, a evolução no modo de pensar dos indivíduos pode se modificar - o que significa dizer que as representações sociais são dinâmicas e móveis.

\section{Representações Sociais nas histórias em quadrinhos de Mauricio de Sousa}

Cossich (2015, n.p) afirma que as histórias em quadrinhos "constituem material de informação e representação da realidade por meio de temas cotidianos e situações semelhantes à vida das pessoas.” Assim, elas podem ser compreendidas como uma forma de comunicação social, muitas vezes refletindo comportamentos presentes na sociedade, propagando ideias e discutindo valores. Nesse sentido, é possível concluir que elas também atuam como veículo das representações sociais na medida em que o leitor atribui sentido ao que é apresentado nas histórias. 
Tal proposição é evidenciada no estudo realizado por Rodrigues e Melo (2012), que objetivou compreender a perspectiva sob a qual o desenvolvimento infanto-juvenil é entendido nas revistas da Turma da Mônica Jovem. Enquanto o senso comum compartilha as representações ligadas à adolescência como uma fase difícil, em que os jovens vivenciam estresse e mudanças constantes de humor desencadeadas pela puberdade, as autoras observaram que episódios que contribuem para a construção de uma nova identidade - mais positiva - para os jovens eram mais recorrentes nessas histórias. Elas ressaltaram a forma com que o enunciador organiza e constrói sua narrativa buscando desconstruir a visão (muitas vezes negativa) atribuída aos adolescentes: destacando as qualidades dos personagens e difundindo-as entre seu público- alvo.

A idealização do presente artigo partiu da leitura da pesquisa conduzida por Vasconcellos et al. (2011). Com o propósito de conhecer as representações sociais sobre o colega com deficiência por parte de 39 crianças de turmas de terceiro e quarto ano do Ensino Fundamental de uma escola estadual do Recife, as autoras utilizaram o conceito de Moscovici (1986) para responder como essa conjuntura afeta social e psicologicamente as crianças nas escolas inclusivas. Em uma das turmas, havia uma criança com surdez, uma com baixa visão, e uma aluna diagnosticada com deficiência mental. Na outra, existia uma criança com baixa visão e uma cega. As autoras fizeram uso de uma abordagem plurimetodológica que envolveu associação livre, desenhos, e grupos focais, para evocar as reações das crianças aos seguintes temas: aluno, aluno com deficiência, colega e colega com deficiência.

Com base na premissa de que a representação social é uma construção feita pelo indivíduo para entender o mundo e se comunicar, as autoras analisaram os dados com base nos pressupostos da Teoria das Representações Sociais. Se as representações servem como instrumento para orientar as práticas sociais e interpretar os acontecimentos do cotidiano, constituem então uma forma significativa de compreender como as crianças pensam e agem em relação aos colegas com deficiência.

Neste momento do trabalho, os desenhos e alguns relatos feitos pelas crianças participantes do estudo serão aqui reproduzidos para fins de comparação com a representação das crianças portadoras de deficiência nas histórias da Turma da Mônica. Iniciaremos com os desenhos de dois dos participantes (2011, p.283): 


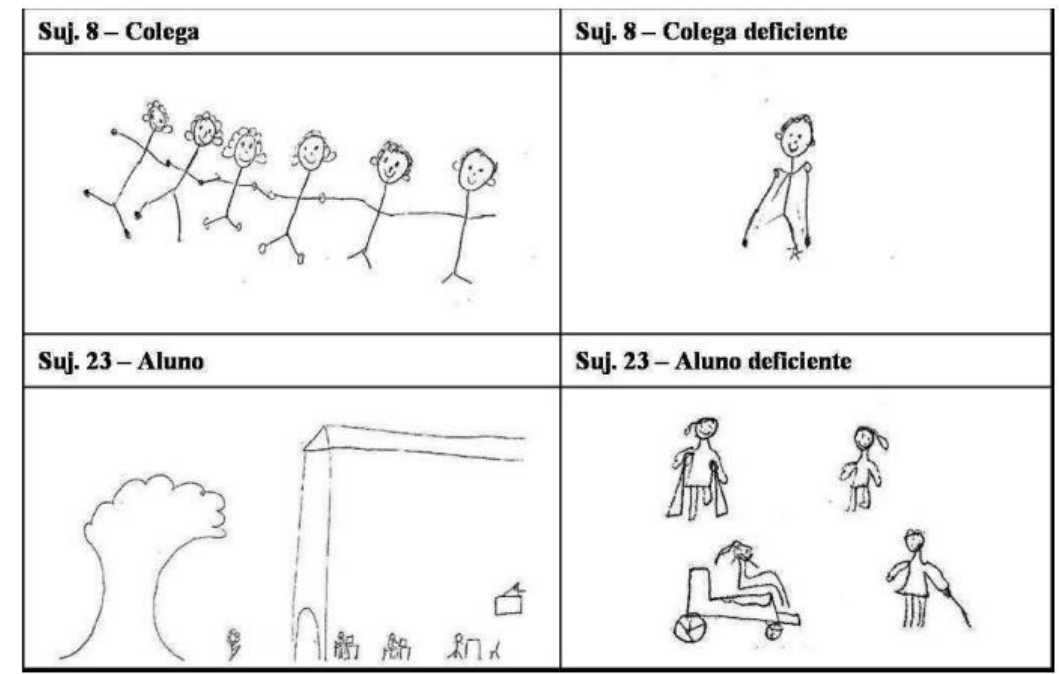

Figura 6 - Desenhos das Crianças sobre Colega, Colega Deficiente, Aluno, Aluno Deficiente

A partir dos desenhos acima, duas palavras antagônicas emergem da narrativa gráfica: coletividade e isolamento. A primeira figura apresenta as crianças de mãos dadas, em união, e utilizando a mão do colega ao lado como um elo ou suporte mútuo. No quadro à direita, é possível observar uma criança deficiente que, embora esboce o mesmo sorriso que os colegas do desenho ao lado, não faz parte de um coletivo, expressando, assim, a possibilidade de representação de um indivíduo isolado dos demais. Além disso, a sensação de apoio mútuo que o primeiro desenho oferece a partir da imagem das mãos dadas é agora substituída pela presença das muletas e bengalas, elementos que podem caracterizar a ideia de que a criança deficiente pode contar apenas com a mutualidade de seu acessório próprio. Segundo constatado pelas autoras do estudo, o colega deficiente foi representado sozinho em um número maior de vezes que o colega sem deficiência.

Outro contraste é perceptível no desenho que reflete os alunos na escola, cuja representação foi de um prédio que acolhe as crianças em seu interior, transmitindo sua sensação de pertencimento ao local e a um grupo. O aluno deficiente, por sua vez, não foi representado dentro da escola ou de qualquer outro cenário, e isso foi sugestivo de sua visão descontextualizada por parte das crianças participantes do estudo. Silva (2006) considera que um dos aspectos geradores de desconforto no contato com pessoas com deficiência é o fato de não sabermos lidar com elas, sendo o estigma o fator que possibilita a identificação. Logo, o relacionamento passa a ser com o rótulo, não com o indivíduo.

Na capa da edição especial Viva as Diferenças!, os personagens com e sem deficiência são retratados no mesmo espaço físico escolar. A noção de coletividade pode ser observada na disposição das crianças deficientes e não deficientes, que estão interagindo no mesmo 
ambiente, sem necessariamente darem as mãos. Ou seja, a ilustração deixa clara a sensação de que todos os personagens - com ou sem deficiência - fazem parte desse espaço:

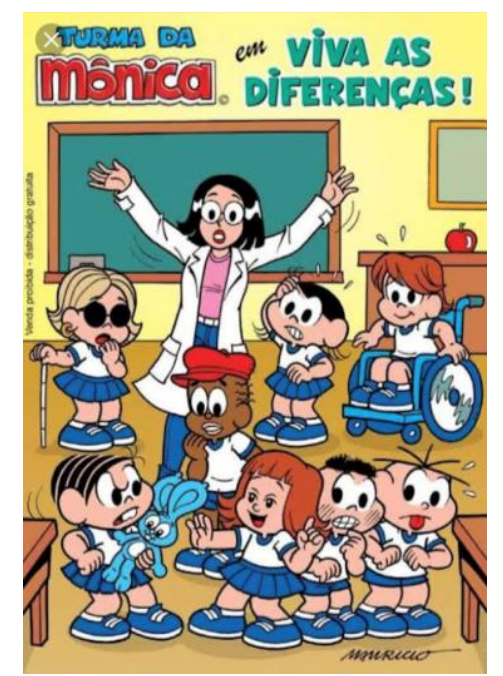

Figura 7 - Capa de "Viva as Diferenças!"

Fonte: http://www.institutomauriciodesousa.org.br/fazendo-a-diferenca/publicacoes/viva-as-diferencas/

Na mesma edição, a historinha relacionada à ilustração da capa termina com a imagem de todas as crianças conversando e indo para casa juntas. É notável, através dos traços no quadrinho e das expressões faciais, que os personagens deficientes e não deficientes se apoiam de forma mútua não por meio de contato físico, e sim através de suas falas. Isso reforça a ideia de que todos podem conviver de forma harmônica e dinâmica, conforme elaborado por Mauricio de Sousa:

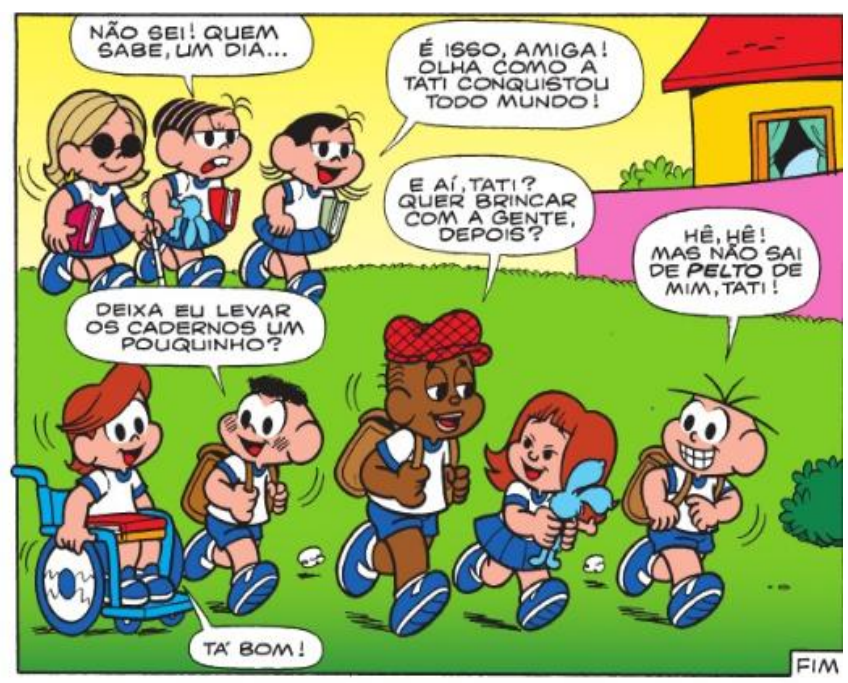

Figura 8 - Personagens com e sem deficiência interagem no mesmo espaço (Revista "Viva as Diferenças!).

Fonte: https://pt.slideshare.net/oliveiraluke/revista-viva-as-diferenas-turma-da-mnica 
Conforme exposto na seção 2 deste artigo, Dorinha é apresentada como simpática e confiante, não aparentando se sentir diferente das outras crianças. Em relação à Figura 4, Fontana e Araújo (2011) também a utilizam em seu estudo, destacando o fato dela explicar sua limitação aos colegas não como uma deficiência, e sim, como uma forma diferente de enxergar, e que isso não a impede de participar das mesmas brincadeiras que os colegas. Em uma historinha, ela deixa Mônica intrigada quando pede para participar da brincadeira de cabra cega e quer tapar os olhos; afinal, "é uma brincadeira":

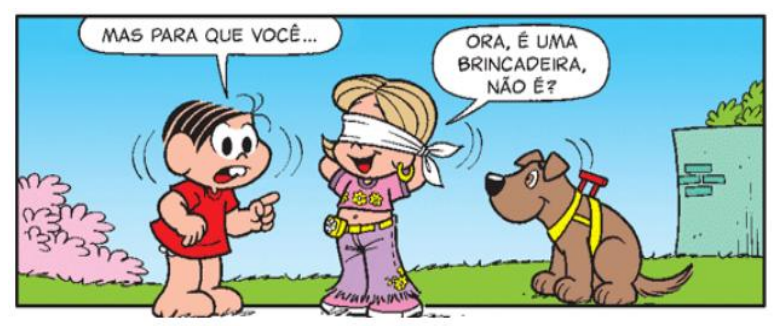

Figura 9 - Dorinha quer tapar os olhos ao brincar de cabra cega (Revista 221).

Fonte: http://no-mundo-da-matemagica.blogspot.com/2013/05/dorinha-uma-nova-amiguinha-da-turmada.html

Sobre esse momento, Rezende e Silvério (2012, p. 269) observaram que:

\begin{abstract}
A escolha dessa brincadeira feita por Maurício para apresentar a personagem traz a percepção de que Dorinha também quer se incluir em seu meio social. Para isso, o autor a coloca como igual, participando da brincadeira de cabra-cega com as crianças. Se ele a tivesse colocado na brincadeira sem a venda, não haveria a percepção de que ela deve ser vista como uma criança como outra, nem diferente, nem excluída. Maurício apresentou o diferente de maneira igual.
\end{abstract}

Assim, a ilustração acima cumpre seu papel de veicular a representação social da criança deficiente como capaz de conviver e brincar com as crianças sem deficiência, e isso tende a gerar entre os leitores dessas histórias a ideia de inclusão. Ao ler esses quadrinhos, é muito provável que as crianças internalizem a naturalidade apresentada pelos personagens e a coloque em prática quando vivenciarem situações semelhantes.

É importante destacar a proposição de Moscovici (2007, p. 37) de que, por serem partilhadas por tantas pessoas, as representações sociais não são pensadas de forma individual, e sim "repensadas, recitadas e reapresentadas". Sobre sua abrangência, Crusoé (2004, p.108) encontra respaldo em Alves-Mazzotti (2000, p. 59) para explicar que:

[...] as representações sociais não são apenas "opiniões sobre" ou "imagens de", mas teorias coletivas sobre o real, sistemas que têm uma lógica e uma linguagem particular, uma estrutura de implicações baseada em valores e conceitos que 'determinam o campo das comunicações possíveis, dos valores e das ideias compartilhadas pelos grupos e regem, subsequentemente, as condutas desejáveis ou admitidas.' 
A citação acima oferece suporte à percepção de Vasconcellos et al. (2011, p. 285), de que "as crianças recebem dos adultos uma série de prescrições de comportamento que visam a proteger os alunos com deficiência, pois estes são considerados frágeis e necessitados de proteção". Contudo, as autoras sinalizam que o efeito colateral dessa conduta supostamente desejável é o aumento da "distância entre as crianças na medida em que impõe limites que vão além daqueles impostos pelas características do aluno em si”. Essa representação, sugestiva de ter sua origem na convivência cotidiana e no conceito de deficiência do discurso adulto, foi identificada nos seguintes trechos dos relatos dos participantes de seu estudo (2011, p. 285):

"Sem bater neles, sem chutar eles, sem empurrar eles" (suj. 7, masculino, nove anos).

"Brinco com ele, mas mesmo assim igual a um bebezinho" (suj. 5, masculino, oito anos).

O excesso de cuidados demonstrado no discurso dos participantes acaba por constituir uma barreira que condena as crianças com deficiência ao isolamento, por serem frágeis e necessitarem ser protegidas de modo a evitar situações de perigo e acidentes. Embora as crianças já nasçam em um mundo estruturado pelas representações sociais, creio que estas podem ser alvo de reestruturação ao pautar-me na proposição de Rodrigues e Melo (2012, p. 146), de que "As histórias em quadrinhos, como uma das formas de mídia, contribuem tanto para veicular as representações sociais já existentes, como também para difundir novas outras". E as historinhas em que o personagem Luca participa ilustram essa realidade: 

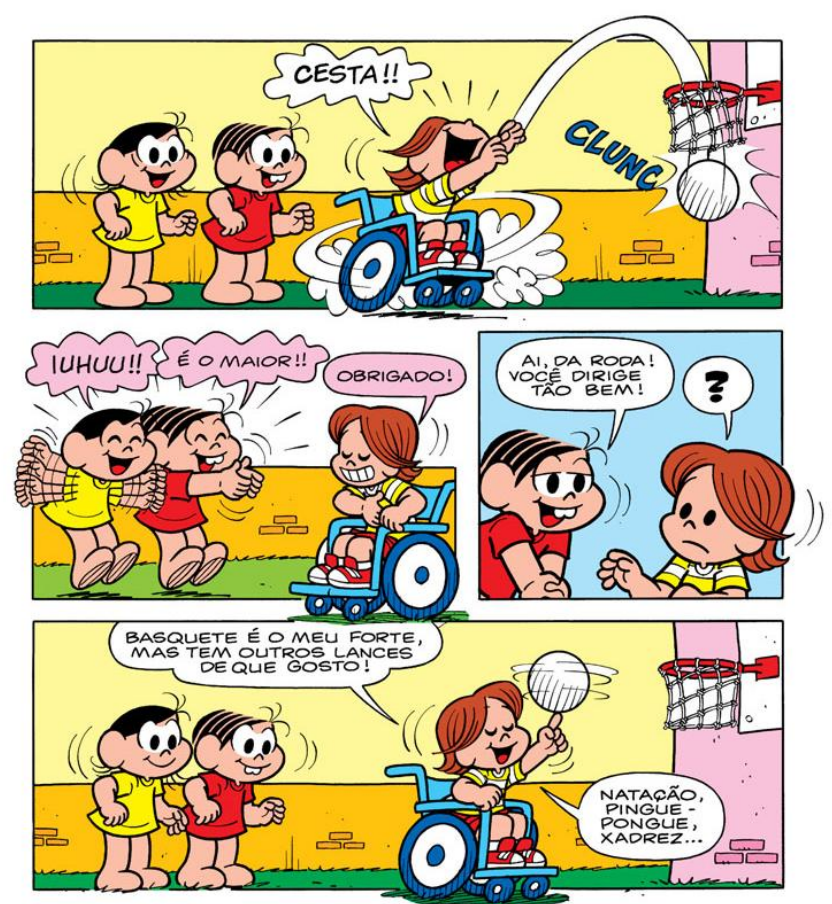

Figura 10 - A desenvoltura de Luca nos esportes (Revista 222).

Fonte: http://turmadamonica.uol.com.br/ummeninosobrerodas/

Ao destacar a desenvoltura de Luca nos esportes, Dall'Agnol (2008, p.54) acrescenta:

Dessa maneira, cria-se uma espécie de equiparação entre a personagem com deficiência e o não deficiente, e, mais uma vez, a deficiência enquanto diferença é obliterada, permitindo a emergência de um universo harmônico e feliz, em que todas as crianças são iguais. Desse modo, as narrativas de Mauricio de Sousa produzem a noção de que ter deficiência não implica, a priori, um impedimento para a inserção na vida cotidiana, e muito menos para a prática de esportes.

Assim, é possível concluir que a presença de personagens com deficiência nas histórias em quadrinhos de Mauricio de Sousa atua positivamente na representação dos deficientes como pessoas capazes e comuns na sociedade, convidando a criança leitora a se identificar com essa visão (WELLICHAN e LINO, 2019). Conforme assevera Dall'Agnol (op.cit., p.68), o leitor é convidado a observar que "ter deficiência não é tão desagradável e tampouco é razão para que não se possa participar do mundo idealizado da infância, marcado, nas histórias de Mauricio de Sousa, pela harmonia e pela amizade incondicional." Logo, o estabelecimento dessa tentativa de inclusão vai de encontro à forma como os deficientes têm sido vistos e tratados historicamente na sociedade.

Mesmo quando as diferenças ocorrem no âmbito comportamental, as histórias da Turma da Mônica podem contribuir para gerar um processo natural de conscientização entre os leitores a respeito das diferenças. Na figura 3 deste trabalho, observa-se que, embora não esteja aparentando interesse em interagir com os personagens Cebolinha e Cascão (sobretudo por não estar fazendo contato visual com eles), André não é excluído daquele espaço, da mesma 
forma que as crianças não se ausentam de sua presença; parece haver ali o respeito à sua atitude diferente. A figura abaixo oferece mais uma demonstração de que, ainda que esteja isolado das demais crianças, o personagem não aparenta estar deslocado:

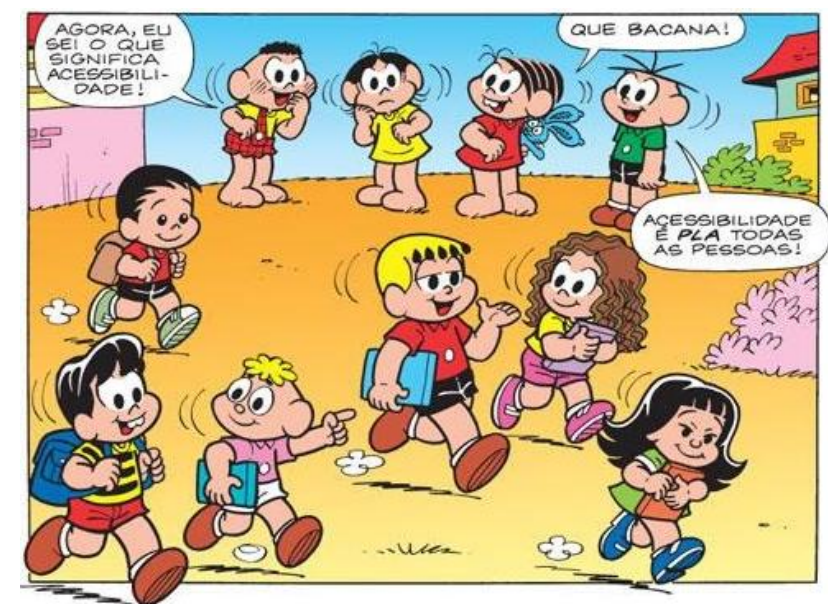

Figura 11 - Acessibilidade é para todas as pessoas (Revista Acessibilidade).

Fonte: http://turmadamonica.uol.com.br/acessibilidade/15.jpg

\section{Considerações Finais}

Conforme observado neste trabalho, imaginar as pessoas com deficiência de forma descontextualizada da sociedade é fruto de um aspecto cultural, constituído por representações sociais compartilhadas ao longo dos tempos, e a exposição a novos valores e saberes pode contribuir para a reestruturação dessas representações. Desde a criação dos primeiros personagens com deficiência, Mauricio de Sousa vem chamando a atenção dos leitores para a importância de sua inclusão e equidade em relação a todos os cidadãos. Conclui-se, assim, que as histórias em quadrinhos não apenas contam histórias, mas veiculam valores que podem contribuir para a formação de indivíduos mais receptivos às diferenças.

Assim, objetivou-se mostrar de que maneira a presença dos personagens com deficiência nas histórias da Turma da Mônica pode contribuir para a mudança das representações sociais dos indivíduos com deficiência, e esse processo pode se iniciar ainda na infância. Considera-se natural que haja um avanço nas ideias e valores dos indivíduos de uma sociedade conforme a sua evolução, e o respeito às diferenças é um fator decisivo para o rompimento de barreiras excludentes - muitas vezes originadas pelo receio de lidar com aquilo que é desconhecido - que ainda perduram em nossos dias. 


\section{REFERÊNCIAS BIBLIOGRÁFICAS}

ALVES-MAZZOTTI, Alda Judith. Representações sociais: desenvolvimentos atuais e aplicações à educação. In: CANDAU, V.M. (org.). Linguagem: espaços e tempo no ensinar e aprender. In: ENCONTRO NACIONAL DE DIDÁTICA E PRÁTICA DE ENSINO (ENDIPE), 10. Rio de Janeiro. Anais... Rio de Janeiro: LP\&A, 2000.

BRASIL. Lei n. 13.146, de 6 de jul. de 2015. Lei Brasileira de Inclusão da Pessoa com Deficiência. Disponível em: http://www.planalto.gov.br/ccivil_03/_Ato2015-

2018/2015/Lei/L13146.htm. Acesso em: 05 de dez. de 2019.

CAMPOS, Viviane.; PICCINATO, Ricardo. (Orgs.). Autismo do diagnóstico ao tratamento: as melhores orientações sobre o universo autista. Bauru, SP: Alto Astral, 2019.

COSSICH, Marília. Histórias em quadrinhos. Uma reflexão sobre a questão da sua representação, 2015. Disponível em: https://biblioo.cartacapital.com.br/historias-emquadrinhos/. Acesso em: 16 de jan. de 2020.

CRUSOÉ, Nilda Margarida Costa. (2004). A teoria das representações sociais em Moscovici e sua importância para a pesquisa em educação. Caderno de Filosofia e Psicologia da Educação, Vitória da Conquista, Ano II, nº 2, p. 105 - 114, 2004.

DALL'AGNOL, Dionara. Representações de deficiência na turma da Mônica, de Mauricio de Souza. 2008, 73f. Dissertação (Mestrado em Educação) - Universidade Luterana do Brasil, Canoas, 2008.

EVIDENCIADOR. Dia do Quadrinho Nacional: as histórias promovendo a inclusão social, 2019. Disponível em: https://www.evidenciador.com.br/entretenimento/dia-doquadrinho-nacional-as-historias-promovendo-a-inclusao-social/, Acesso em: $05 \mathrm{de} \mathrm{dez}$. de 2019.

FONTANA, Edna; ARAÚJO, Fabíola Elisa Um Caso "Especial": a Personagem "Dorinha" da Turma da Mônica. Perspectivas Contemporâneas, Campo Mourão, v.6, n.1, p. 1-17, jan./jun. 2011.

FORTUNATO, Ivan. Maurício de Sousa e meio século de sucesso com a sua Turma da Mônica. In: Sumaré - Revista Acadêmica Eletrônica. Edição 4, São Paulo, 2010. Disponível em: https://docplayer.com.br/53203674-Mauricio-de-sousa-e-meio-seculo-de-sucesso-com-asua-turma-da-monica.html, Acesso em: 20 de jan. de 2020.

FRAZÃO, Dilva. Mauricio de Sousa. Ebiografia.com, 2018. Disponível em: https://www.ebiografia.com/mauricio_de_sousa/. Acesso em: 05 de dez. de 2019.

GUARESCHI, Pedrinho. A.; JOVCHELOVITCH, Sandra. (Orgs). Textos em representações sociais. $7^{\mathrm{a}}$ ed. Petrópolis: Vozes, 2002.

LOPES, Gustavo Casimiro. O preconceito contra o deficiente ao longo da história. EFDeportes.com. Buenos Aires, ano 17, nº 176, janeiro de 2013. Disponível em: 
https://www.efdeportes.com/efd176/o-deficiente-ao-longo-da-historia.htm, Acesso em: 24 de jan. de 2020.

MOSCOVICI, Serge. Introducción: el campo de la psicología social. In: MOSCOVICI, S. Psicología Social. Barcelona: Paidós, p. 17-37, 1986.

RJ: Vozes, 2007.

Representações sociais: investigação em pesquisa social. $5^{\mathrm{a}}$ ed. Petrópolis,

OLIVEIRA, Márcio S. B. S. Representações sociais e sociedades: a contribuição de Serge Moscovici. Revista Brasileira de Ciências Sociais, v. 19, n. 55, p. 180-6, jun. 2004.

REVISTA AUTISMO. Nas bancas, personagem autista André é capa da revista da Turma da Mônica de julho, 2019. Disponível em: https://www.revistaautismo.com.br/naocategorizado/nas-bancas-personagem-autista-andre-e-capa-da-revista-da-turma-da-monica-dejulhol, Acesso em: 21 de jan. de 2020.

REZENDE, Lucinea Aparecida.; SILVÉRIO, Luciana Begatini Ramos. Leitura e educação representações da inclusão social na obra de Maurício de Sousa. Cadernos de Letras da UFF - Dossiê: Palavra e imagem, v. 44, n. 1 255-276, 2012.

RIBAS, João. Preconceito Contra as Pessoas com Deficiência: as relações que travamos com o mundo. São Paulo, Cortez, 2007.

RODRIGUES, Neide Nunes.; MELO, Mônica Santos de Souza. Representações sociais nos quadrinhos de Maurício de Sousa. Leia Escola , v. 12, p. 131-148, 2012.

SASSAKI, Romeu Kazumi Como chamar as pessoas que têm deficiência? 2005.

Disponível em: http://napne.ifbaiano.edu.br/portal/?p=11, Acesso em: 25 de jan. de 2020.

Como chamar as pessoas que têm deficiência? 2014. Disponível em: https://www.diversa.org.br/artigos/como-chamar-pessoas-que-tem-deficiencia/, Acesso em: 05 de dez. de 2019.

SILVA, Luciene. M. da. O estranhamento causado pela Deficiência: preconceito e experiência. Revista Brasileira de Educação, Bahia, v. 11, n. 33, p. 424-434, set./dez. 2006.

SILVA, Maria Isabel da. Por que a terminologia "pessoas com deficiência"? 2012. Disponível em: https://www.selursocial.org.br/porque.html, Acesso em: 26 de dez. de 2019.

VASCONCELOS, Victor. Turma da Mônica possui personagens com deficiências, 2014. Disponível em: http://www.sembarreiras.jor.br/2014/07/03/turma-da-monica-possuipersonagens-com-deficiencias/, Acesso em: 05 de dez. de 2019.

VASCONCELLOS, Karina. Mendonça; SANTOS, Maria de Fátima Souza; ALMEIDA, Angela Maria Oliveira. A representação social do aluno com deficiência na educação inclusiva: o olhar das crianças. Práxis Educativa, Ponta Grossa, v. 6, n. 2, p. 277-287, jul/dez. 2011. 
VIDA MAIS LIVRE. O desenhista Mauricio de Sousa fala sobre a criação de personagens com deficiências, 2012. Disponível em:

https://vidamaislivre.com.br/especiais/o-desenhista-mauricio-de-sousa-fala-sobre-a-criacaode-personagens-com-deficiencias/, Acesso em: 05 de dez. de 2019.

WELLICHAN, Daniele da Silva Pinheiro; LINO, Carla Cristine Tescaro Santos. A inclusão que está nos quadrinhos: como os personagens podem divertir e ensinar sobre as pessoas com deficiência. DOXA: Revista Brasileira de Psicologia e Educação, [S.l.], p. 44-61, feb. 2019. Disponível em: 〈https://periodicos.fclar.unesp.br/doxa/article/view/12693/8644>, Acesso em: 24 de fev. 2020.

\section{REVISTAS EM QUADRINHOS}

TURMA DA MÔNICA. Dorinha, a nova amiguinha! São Paulo: Globo, n. 221, 2004.

Disponível em: http://turmadamonica.uol.com.br/dorinhaanovaamiguinha/, Acesso em: 25 de jan. de 2020.

. Da roda, o novo amiguinho. São Paulo: Globo, n. 222, 2004. Disponível em: http://turmadamonica.uol.com.br/ummeninosobrerodas/, Acesso em: 25 de jan. de 2020.

. Acessibilidade. São Paulo: Mauricio de Sousa Produções, 2006. Disponível em: http://turmadamonica.uol.com.br/acessibilidade/, Acesso em: 26 de jan. de 2020.

Que fim levou Sansão? São Paulo: Globo, n. 239, p.35-42, 2006.

2007.

. Um amiguinho diferente. São Paulo: Maurício de Sousa, p.3-15,

p. 11-18, 2009.

. Viva as diferenças! São Paulo: Instituto Metasocial e Mantecorp, 